\title{
ARTICLE
}

\section{Investigation of exotic stable calcium carbides using theory and experiment}

Yan-Ling Li , Sheng-Nan Wang ${ }^{2}$, Artem R. Oganov $2,3,4,5$, Huiyang Gou ${ }^{6}$, Jesse S. Smith ${ }^{7}$ \& Timothy A. Strobel ${ }^{6}$

It is well known that pressure causes profound changes in the properties of atoms and chemical bonding, leading to the formation of many unusual materials. Here we systematically explore all stable calcium carbides at pressures from ambient to $100 \mathrm{GPa}$ using variable-composition evolutionary structure predictions using the USPEX code. We find that $\mathrm{Ca}_{5} \mathrm{C}_{2}, \mathrm{Ca}_{2} \mathrm{C}, \mathrm{Ca}_{3} \mathrm{C}_{2}, \mathrm{CaC}, \mathrm{Ca}_{2} \mathrm{C}_{3}$ and $\mathrm{CaC}_{2}$ have stability fields on the phase diagram. Among these, $\mathrm{Ca}_{2} \mathrm{C}$ and $\mathrm{Ca}_{2} \mathrm{C}_{3}$ are successfully synthesized for the first time via high-pressure experiments with excellent structural correspondence to theoretical predictions. Of particular significance is the base-centred monoclinic phase (space group $\mathrm{C} 2 / \mathrm{m}$ ) of $\mathrm{Ca}_{2} \mathrm{C}$, a quasi-twodimensional metal with layers of negatively charged calcium atoms, and the primitive monoclinic phase (space group $P 2_{1} / c$ ) of $\mathrm{CaC}$ with zigzag $\mathrm{C}_{4}$ groups. Interestingly, strong interstitial charge localization is found in the structure of $R-3 m-C_{5} C_{2}$ with semi-metallic behaviour.

\footnotetext{
${ }^{1}$ Laboratory for Quantum Design of Functional Materials, School of Physics and Electronic Engineering, Jiangsu Normal University, 221116 Xuzhou, China. ${ }^{2}$ Department of Geosciences, State University of New York, Stony Brook, New York 11794-2100, USA. ${ }^{3}$ Center for Materials by Design, Institute for Advanced Computational Science, State University of New York, Stony Brook, New York 11794-2100, USA. ${ }^{4}$ Moscow Institute of Physics and Technology, 9 Institutskiy lane, Dolgoprudny city, Moscow Region 141700, Russia. ${ }^{5}$ Northwestern Polytechnical University, Xi'an 710072, China. ${ }^{6}$ Geophysical Laboratory, Carnegie Institution of Washington, Washington, District of Columbia 20015, USA. ${ }^{7}$ High Pressure Collaborative Access Team, Geophysical Laboratory, Carnegie Institution of Washington, Argonne, Illinois 60439, USA. Correspondence and requests for materials should be addressed to Y.-L.L. (email:ylli@jsnu.edu.cn) or to A.R.O. (email: artem.oganov@stonybrook.edu) or to T.A.S. (email: tstrobel@carnegiescience.edu).
} 
U nexpected chemical reactions can happen under extreme conditions, with emergence of rich phase diagrams and materials possessing intriguing properties. Recently, by combining variable-composition structure prediction methods with first-principles total energy calculations ${ }^{1}$, pressurecomposition $(P-x)$ phase diagrams were predicted for such binary systems as $\mathrm{Mg}-\mathrm{O}$ (ref. 2) and $\mathrm{Na}-\mathrm{Cl}$ (ref. 3). In both cases, the predicted unexpected compounds have been successfully synthesized ${ }^{3,4}$. Elemental carbon and calcium both exhibit rich diversity of stable and metastable phases under pressure $^{5-7}$. Compressed calcium shows unique structural and electronic properties and exhibits the highest recorded superconducting critical temperature among pure elements ${ }^{8}$. For carbon, only graphite and diamond are experimentally known as thermodynamically stable solids (graphite is thermodynamically stable at ambient condition and diamond under high pressure), although numerous metastable phases are known. For example, by applying pressure to graphite at low temperatures, a new superhard carbon allotrope was found, and its properties match those of one of the theoretically predicted structures (Mcarbon $)^{9-12}$. For the $\mathrm{Ca}-\mathrm{C}$ system, the well-known $\mathrm{Ca}$ carbides include $\mathrm{CaC}_{2}$ and $\mathrm{CaC}_{6}$, whose high-pressure behaviours have been studied experimentally ${ }^{13-15}$ and by $a b$ initio calculations ${ }^{16-}$ 20. An interesting structural evolution has been uncovered under pressure: carbon atoms polymerize from dumbbells to onedimensional (1D) chains to ribbons to two-dimensional (2D) graphene sheets in compressed $\mathrm{CaC}_{2}$ (ref. 16) and from graphite sheets to a mixed $s p^{2}-s p^{3}$ structure in $\mathrm{CaC}_{6}$ (ref. 20). In addition, superconductivity was predicted in metallic high-pressure phases of $\mathrm{CaC}_{2}$ with critical temperatures comparable to those observed in $\mathrm{CaC}_{6}$ (ref. 16).

Here, using variable-composition structure prediction code USPEX $^{1,9,21}$, the pressure-composition phase diagram of the $\mathrm{Ca}-\mathrm{C}$ system was explored in order to fully understand the structural diversity and evolution of the $\mathrm{C}-\mathrm{C}$ bonding types under high pressure. This resulted in five newly predicted stable stoichiometries $\left(\mathrm{Ca}_{5} \mathrm{C}_{2}, \mathrm{Ca}_{2} \mathrm{C}, \mathrm{Ca}_{3} \mathrm{C}_{2}, \mathrm{CaC}\right.$ and $\left.\mathrm{Ca}_{2} \mathrm{C}_{3}\right)$ with diverse carbon arrangements: isolated atoms in $\mathrm{Ca}_{2} \mathrm{C}$, hitherto unknown zigzag tetramers in $\mathrm{CaC}$, and ribbons consisting of five-membered rings in $\mathrm{CaC}_{2}$. Two phases $\left(\mathrm{Ca}_{2} \mathrm{C}\right.$ and $\mathrm{Ca}_{2} \mathrm{C}_{3}$ ) were confirmed experimentally via in situ synchrotron powder X-ray diffraction (PXRD) measurements. Most surprising is that the low-pressure phase (monoclinic $\mathrm{C} 2 / \mathrm{m}$ structure) of $\mathrm{Ca}_{2} \mathrm{C}$ exhibits quasi-2D metallic behaviour and contains negatively charged calcium atoms. In addition, strong interstitial electron localization was found in the newly predicted $R-3 m$ phase of $\mathrm{Ca}_{5} \mathrm{C}_{2}$, just as in compressed elements $\mathrm{Li}$ (ref. 22), $\mathrm{Na}$ (ref. 23) and $\mathrm{Ca}$ (ref. 6), as well as in the compound $\mathrm{Mg}_{3} \mathrm{O}_{2}$ (ref. 2).

\section{Results}

Convex hull. We have used the ab initio evolutionary algorithm USPEX $^{1,9,21}$, which can simultaneously find stable stoichiometries and the corresponding structures in multicomponent systems, to explore stable $\mathrm{Ca}-\mathrm{C}$ compounds and their structures. In these calculations, all stoichiometries were allowed (with the constraint that the total number of atoms in the unit cell be below 16 atoms), and calculations were performed at 10, 20, 40, 80 and $100 \mathrm{GPa}$. The pressure-composition phase diagram of the $\mathrm{Ca}-\mathrm{C}$ system is given in Fig. 1a, in which the convex hull was obtained from the calculated enthalpies of the most stable structures for each composition at a given pressure. Thermodynamically, the convex hull at a given pressure connects the phases that are stable against decomposition into other binaries or the elements.
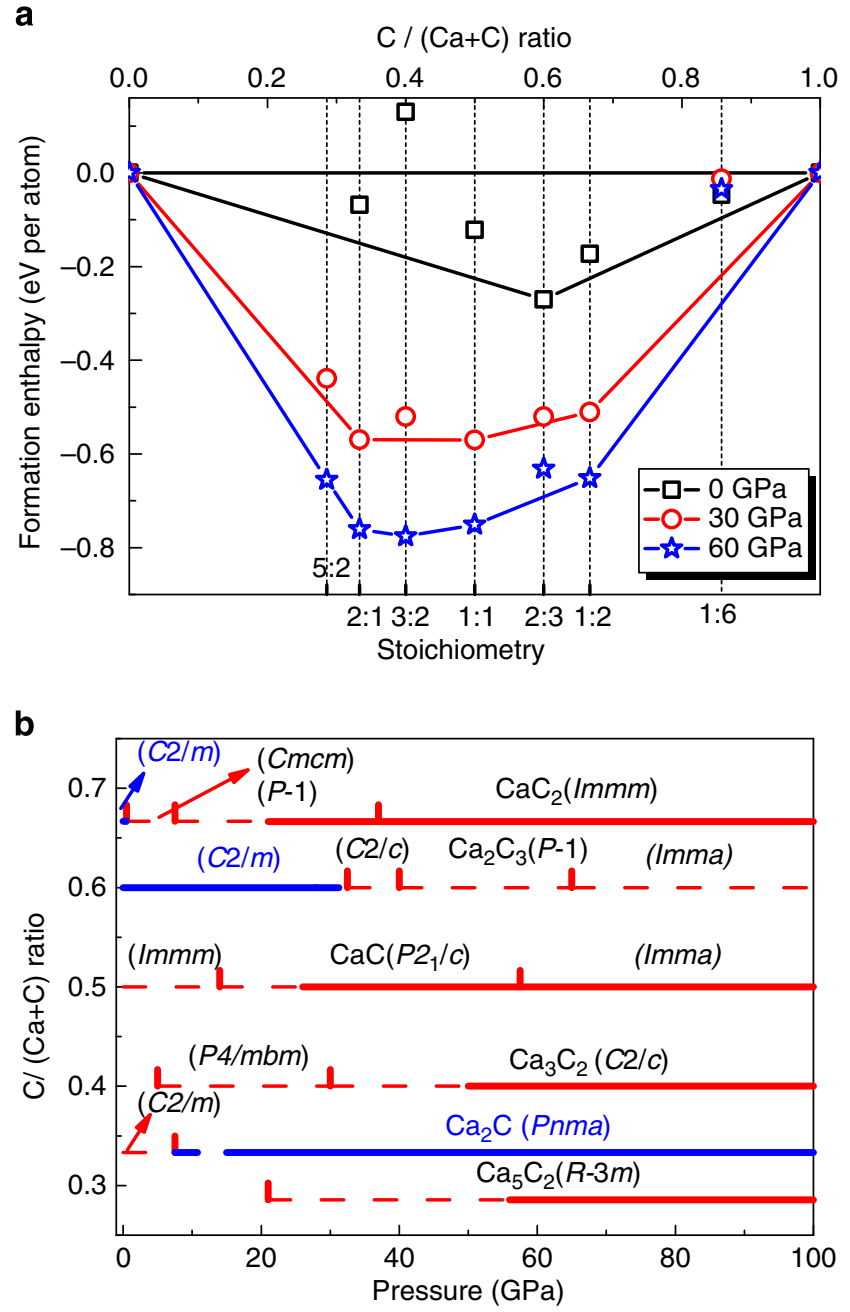

Figure 1 | Stability of new calcium carbides. (a) Convex hull diagram for the $\mathrm{Ca}-\mathrm{C}$ system at selected pressures. At a given pressure, the compounds located on the convex hull are thermodynamic stable. (b) Pressurecomposition phase diagram of the $\mathrm{Ca}-\mathrm{C}$ system. Thick solid lines represent thermodynamically stable phases and dashed lines represent metastable phases (Red lines represent metal and blue semiconductor).

Thermodynamically stable or metastable phases. Using variable-composition evolutionary searches, we found that $\mathrm{Ca}_{5} \mathrm{C}_{2}$, $\mathrm{Ca}_{2} \mathrm{C}, \mathrm{Ca}_{3} \mathrm{C}_{2}, \mathrm{CaC}, \mathrm{Ca}_{2} \mathrm{C}_{3}$ and $\mathrm{CaC}_{2}$ have thermodynamic stability fields on the phase diagram: $\mathrm{Ca}_{2} \mathrm{C}_{3}$, stable from 0 to $28 \mathrm{GPa}$; $\mathrm{Ca}_{5} \mathrm{C}_{2}$, stable above $58 \mathrm{GPa} ; \mathrm{Ca}_{2} \mathrm{C}$, stable above $14 \mathrm{GPa} ; \mathrm{Ca}_{3} \mathrm{C}_{2}$, stable from $\sim 50 \mathrm{GPa}$; $\mathrm{CaC}$, stable above $26 \mathrm{GPa}$; and $\mathrm{CaC}_{2}$, stable above $21 \mathrm{GPa}$ (see Figs $1 \mathrm{~b}$ and 2). All crystallographic parameters are listed in Supplementary Table 1. For all the newly predicted structures, calculated phonon dispersion relations confirmed their dynamical stability (see Supplementary Figs 1-5 and Supplementary Note 1). Surprisingly, our theoretical calculations show that the known phases of $\mathrm{CaC}_{2}$ and $\mathrm{CaC}_{6}$ are thermodynamically metastable at normal conditions (see Fig. 1a); $\mathrm{CaC}_{2}$ is thermodynamically stable only above $21 \mathrm{GPa}$, and $\mathrm{CaC}_{6}$ does not have a thermodynamic stability field $\left(\mathrm{BaC}_{6}\right.$ is thermodynamically stable in the Ba-C system at 1 atm (ref. 24)). We also explored metastable phases of $\mathrm{Ca}_{2} \mathrm{C}$ and $\mathrm{CaC}$ at lower pressure. The most stable low-pressure phase obtained for $\mathrm{Ca}_{2} \mathrm{C}$ has $C 2 / m$ symmetry and that of $\mathrm{CaC}$ has $\mathrm{Immm}$ symmetry. The dynamical stability of these two thermodynamically metastable phases was confirmed via phonon calculations (Supplementary Figs 6 and 7). 
a

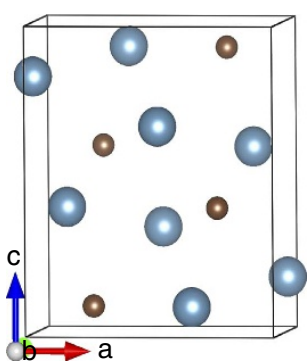

d

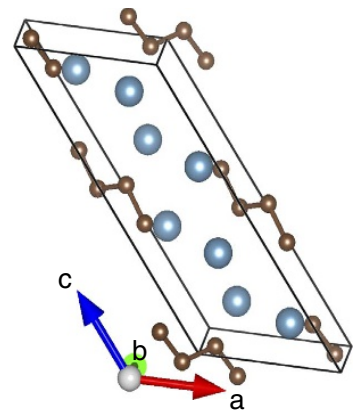

b

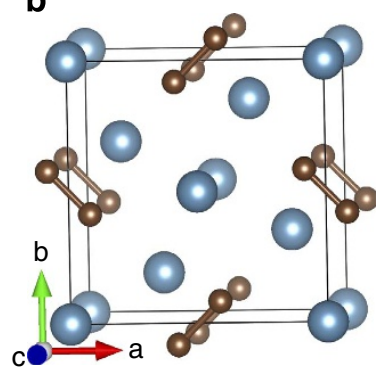

C

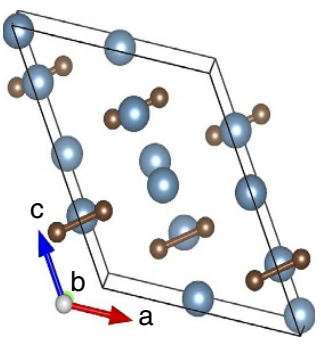

e

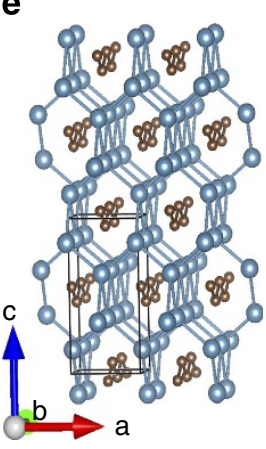

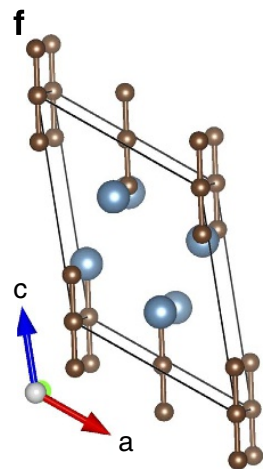

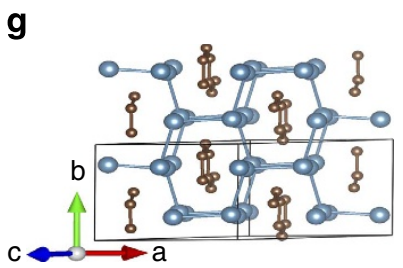

h

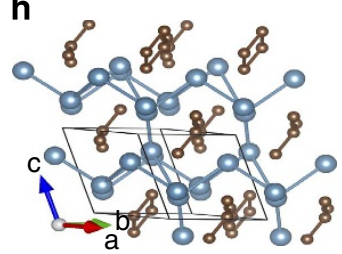

i
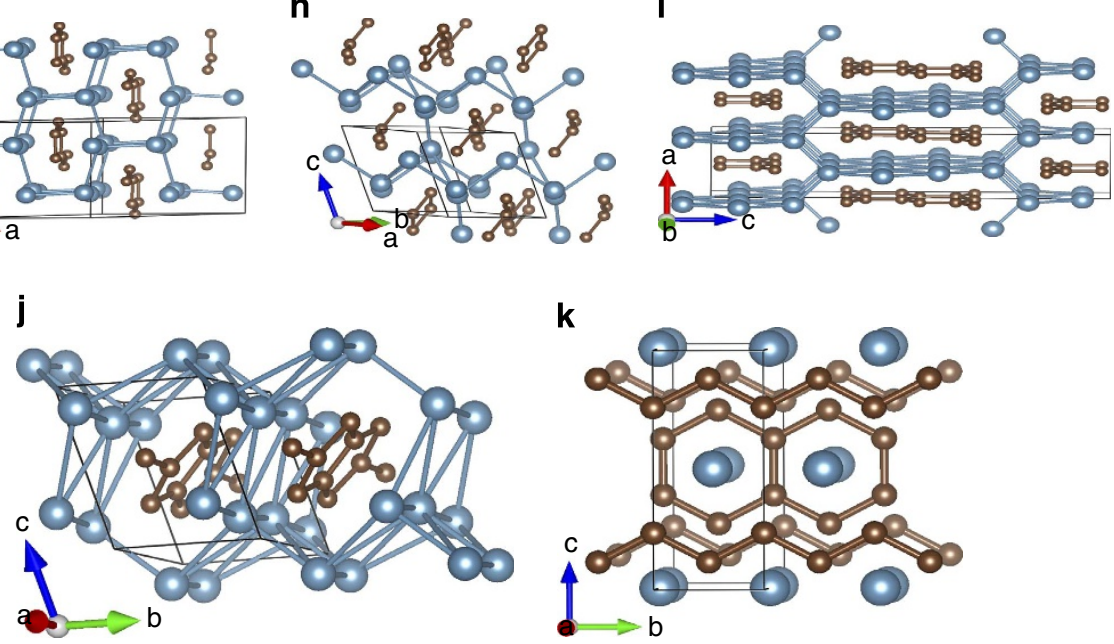

Figure 2 | The predicted crystal structures of stable $\mathbf{C a}-\mathbf{C}$ compounds. (a) Thermodynamically stable Pnma structure of $\mathrm{Ca}_{2} \mathrm{C}$. (b) The metastable low pressure $\mathrm{P} 4 / \mathrm{mbm}$ structure of $\mathrm{Ca}_{3} \mathrm{C}_{2}$. (c) Thermodynamiclly stable high pressure $\mathrm{C} 2 / \mathrm{c}$ structure of $\mathrm{Ca}_{3} \mathrm{C}_{2}$. (d) Thermodynamically stable $P 2_{1} / c$ structure of $\mathrm{CaC}$. (e) Thermodynamically stable high pressure Imma structure of $\mathrm{CaC}$. (f) $\mathrm{Ca}_{2} \mathrm{C}_{3}$ crystallizes in $\mathrm{C} 2 / \mathrm{m}$ structure at pressures up to $28 \mathrm{GPa}$. (g) Thermodynamically metastable $\mathrm{C} 2 / \mathrm{c}$ structure of $\mathrm{Ca}_{2} \mathrm{C}_{3}$. (h) Thermodynamically metastable $P-1$ structure of $\mathrm{Ca}_{2} \mathrm{C}_{3}$. (i) Thermodynamically metastable high pressure $I m m a$ of $\mathrm{Ca}_{2} \mathrm{C}_{3}$. (j) Thermodynamically stable $P$-1 structure of $\mathrm{CaC}_{2}$. (k) Thermodynamically stable $I m m m$ structure of $\mathrm{CaC}_{2}$. The blue and brown spheres represent calcium and carbon atoms, respectively.

In order to analyse these predicted structures, we recall that the $\mathrm{C}-\mathrm{C}$ bond length depends on the bond order, and at $1 \mathrm{~atm}$ these lengths are $1.20 \AA$ for the triple $\mathrm{C}-\mathrm{C}$ bond, $1.33 \AA$ for double bond and $1.54 \AA$ for single $\mathrm{C}-\mathrm{C}$ bond. The carbon patterns predicted for calcium carbides, on the basis of calculations presented in this work, are plotted in Fig. 3. The carbon patterns together with their pressure range of existence in calcium carbides are summarized in Fig. 4 and in Supplementary Table 2. Combining this knowledge with the results of Bader analysis (see Supplementary Table 1), we unravel very diverse chemistry. From the results of the Bader analysis, one can clearly see the correlation between the charge and volume: negatively charged calcium atoms occupy significantly greater volume. In addition, we observe the decrease in $\mathrm{C}-\mathrm{C}$ bond order from triple to double to single bonds as pressure increases. Note, however, that at pressures up to $100 \mathrm{GPa}$, the carbon-richest stable compound is $\mathrm{CaC}_{2}$. Below we consider the predicted phases in order of increasing carbon content.

$\mathrm{Ca}_{5} \mathrm{C}_{2}$. The stable structure of $\mathrm{Ca}_{5} \mathrm{C}_{2}$ has a $R-3 m$ symmetry. It is a semi-metal (see Supplementary Fig. 8) and is thermodynamically stable at pressures ranging from $58 \mathrm{GPa}$ to at least $100 \mathrm{GPa}$ (see Fig. 4). This phase has novel structural features: it can be described as consisting of alternating $\mathrm{CaC}_{2}$ layers (where $\mathrm{Ca}$ is octahedrally coordinated by $\mathrm{C}$ atoms) and layers with 
a b

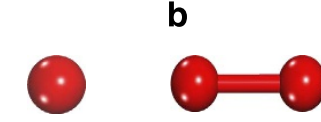

C
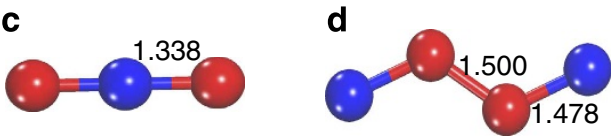

e
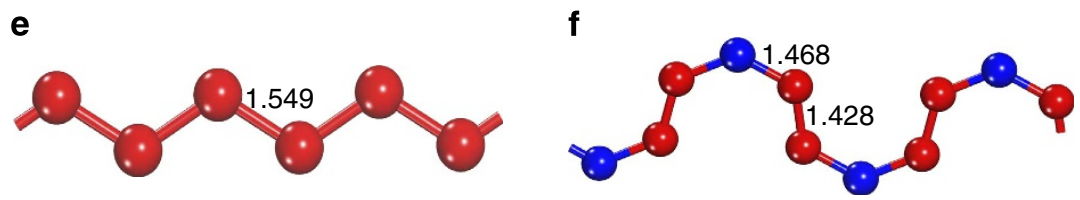

g

h
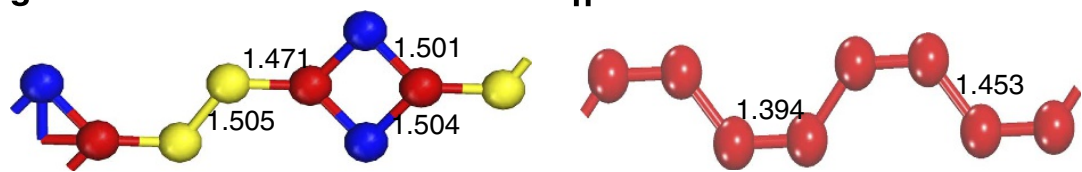

i

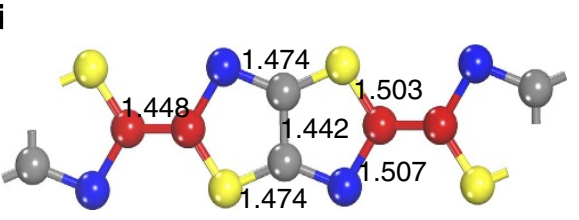

j
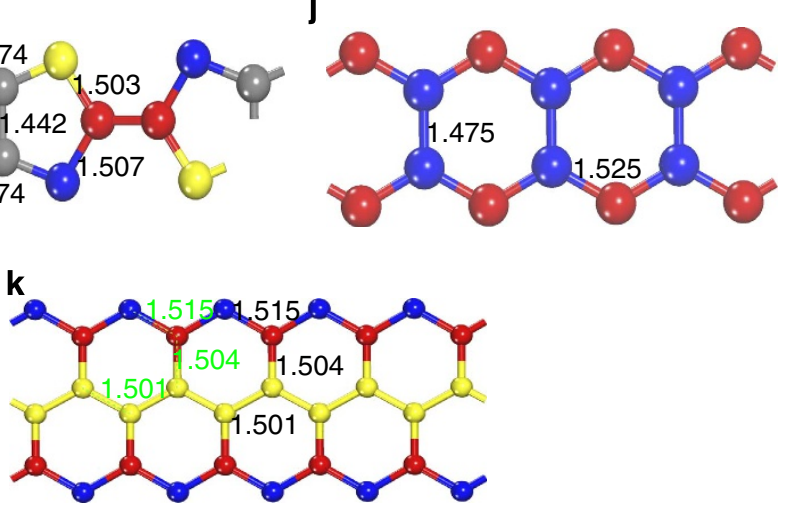

Figure 3 | Carbon patterns in the Ca-C system. (a) The isolated carbon anions in the Pnma structure of $\mathrm{Ca}_{2} \mathrm{C}$. (b) Carbon dimers observed in the $\mathrm{C} 2 / m$ structure of $\mathrm{Ca}_{2} \mathrm{C}, \mathrm{P} 4 / \mathrm{mbm}$ and $\mathrm{C} 2 / \mathrm{c}$ structures of $\mathrm{Ca}_{3} \mathrm{C}_{2}, I \mathrm{mmm}$ structure of $\mathrm{CaC}$, and $\mathrm{C} 2 / \mathrm{m}$ or $\mathrm{C} 2 / \mathrm{c}$ structures of $\mathrm{CaC}_{2}$. (c) The carbon trimer occurs in the $\mathrm{C} 2 / \mathrm{m}$ structure of $\mathrm{Ca}_{2} \mathrm{C}_{3}$ at zero pressure. (d) Zigzag $\mathrm{C}_{4}$ groups observed in $P 2_{1} / c$ structure of $\mathrm{CaC}$ at $20 \mathrm{GPa}$. (e) Zigzag carbon chains in the Imma structure of $\mathrm{CaC}$ at $58 \mathrm{GPa}$. (f) Carbon chains with two types of carbon-carbon bondings in $\mathrm{C} 2 / \mathrm{c}$ structure of $\mathrm{Ca}_{2} \mathrm{C}_{3}$ at $34.5 \mathrm{GPa}$. ( $\mathrm{g}$ ) $\mathrm{Carbon}$ chains with four types of carbon-carbon bongdings in $\mathrm{P}-1$ structure of $\mathrm{Ca}_{2} \mathrm{C}_{3}$ at $40 \mathrm{GPa}$. (h) Armchair carbon chains in the $\mathrm{Cmcm}$ structure of $\mathrm{CaC}$ at $4 \mathrm{GPa}$. (i) $\mathrm{Carbon}$ stripes in the $P-1$ structure of $\mathrm{CaC}_{2}$ at $20 \mathrm{GPa}$. (j) Carbon ribbons in the $1 \mathrm{mmm}$ structure of $\mathrm{CaC}_{2}$ at $10 \mathrm{GPa}$. (k) Carbon ribbons in the Imma structure of $\mathrm{Ca}_{2} \mathrm{C}_{3}$ at $65 \mathrm{GPa}$. Bond lengths (in $\AA$ ) are given. The inequivalent $\mathrm{C} 1, \mathrm{C} 2, \mathrm{C} 3$, and $\mathrm{C} 4$ (occupying different Wyckoff positions in the unit cell, see Supplementary Table 1) are shown by red, blue, yellow, and grey spheres, respectively.

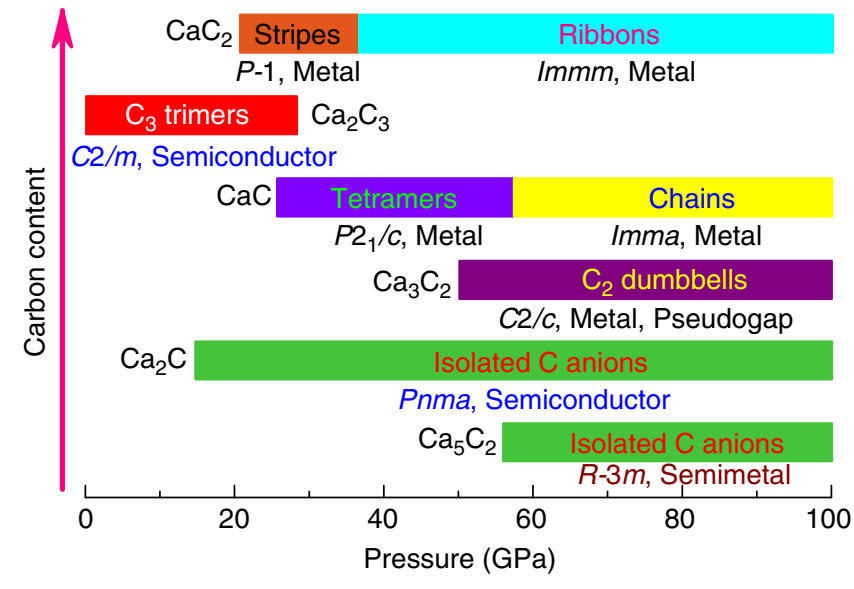

Figure 4 | Carbon arrangement with increasing carbon content. Only thermodynamically stable phases are shown (For metastable phases, see Supplementary Table 2). Additionally, the conducting properties are shown.

composition $\mathrm{Ca}_{4}$. The electron localization function distribution in $\mathrm{Ca}_{5} \mathrm{C}_{2}$ shows strong charge transfer from $\mathrm{Ca}$ to $\mathrm{C}$. Non-nuclear charge density maxima are located in the $\mathrm{Ca}_{4}$ layer as plotted in
Fig. 5 (electron localization function $=0.75$ at $60 \mathrm{GPa}$ ). Bader charges are +1.039 for $\mathrm{Ca} 1,+0.823$ for $\mathrm{Ca} 2,+0.973$ for $\mathrm{Ca} 3$ and -0.459 for the interstitial electron density maximum.

$\mathrm{Ca}_{2} \mathrm{C}$. Known alkali earth methanides include well-know $\mathrm{Be}_{2} \mathrm{C}$ $(F m-3 m, \mathrm{Z}=4)$ and $\mathrm{Mg}_{2} \mathrm{C}$ (antifluorite) recently synthesized by Kurakevych et al. ${ }^{25}$ However, no theoretical or experimental information has been reported on the methanide $\mathrm{Ca}_{2} \mathrm{C}$ (ref. 26). According to our calculations, $\mathrm{Ca}_{2} \mathrm{C}$ is thermodynamically stable above $15 \mathrm{GPa}$ (space group Pnma $(\mathrm{Z}=4)$ ). For Pnma-Ca ${ }_{2} \mathrm{C}$ we observe the largest negative charge of carbon atoms among all these phases: -2.321 . In this semiconducting phase with band gap of $0.64 \mathrm{eV}$ at $14 \mathrm{GPa}$ (see Supplementary Fig. 9), C atoms are isolated and one can represent this compound as a carbide with an idealized charge transfer scheme $\left(\mathrm{Ca}^{2+}\right)_{2} \mathrm{C}^{4-}$ adhering to the Zintl concept. Metallic metastable $\mathrm{C} 2 / \mathrm{m}-\mathrm{Ca}_{2} \mathrm{C}$ has a unique structure, consisting of alternating layers of stoichiometry $\mathrm{Ca}_{2}\left(\mathrm{C}_{2}\right)$ and $\mathrm{Ca}_{2}$ (two kinds of calcium atoms play distinctly different roles, see Fig. 6 a), and these layers have net charges of +0.582 and -0.582 , respectively (see Supplementary Table 1 ). What is unusual is that the Ca layer is negatively charged, that is, it is a reservoir of electrons. To further analyse this phenomenon, it is instructive to look first at the $\mathrm{Ca}_{2}\left(\mathrm{C}_{2}\right)$ layer. This $\mathrm{C}_{2}$ group 


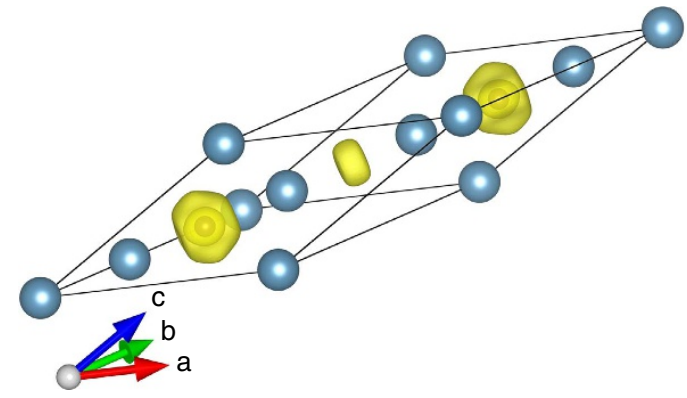

Figure 5 | Electron localization function (ELF) of $R-3 m-C_{5} C_{2}$ at $60 \mathrm{GPa}$. The isosurface ELF $=0.75$ is shown. The observed interstitial electron charge accumulation shows that $\mathrm{Ca}_{5} \mathrm{C}_{2}$ with $R-3 \mathrm{~m}$ symmetry is an electride.

can be represented as having a triple $\mathrm{C}-\mathrm{C}$ bond and its ideal charge is -2 (Bader charge is -1.892), and if each $\mathrm{Ca}$ had the ideal charge of +2 , the total charge of the $\mathrm{Ca}_{2}\left(\mathrm{C}_{2}\right)$ layer would be +2 , and two electrons would be transferred to the $\mathrm{Ca}_{2}$ layer (see Supplementary Table 1 ). In reality, the $\mathrm{C}-\mathrm{C}$ bond here has a somewhat lower order (C-C distance is $1.28 \AA$ at $5 \mathrm{GPa})$ and therefore takes more electrons from $\mathrm{Ca}$ atoms, leaving less for the $\mathrm{Ca}_{2}$ layer, but not changing the picture qualitatively. To our knowledge, this is the first example of negatively charged metal atoms in a compound with more electronegative atoms. Note the enormous difference of Bader volumes of the positively and negatively charged $\mathrm{Ca}$ atoms $\left(16.570\right.$ versus $\left.41.901 \AA^{3}\right)$. One can expect that the electrons in the Ca layer are very loosely bound, and the work function of this compound can be expected to be extremely low. The density of states of the metastable $\mathrm{C} 2 / \mathrm{m}$ phase of $\mathrm{Ca}_{2} \mathrm{C}$ reveals a remarkable step-like feature near the bottom of the valence band, followed by a nearly constant density of states (see Fig. 6b), presenting an example of a quasi-2D electronic structure as observed in Li-Be alloys ${ }^{27}$. The calculated Fermi surface of $\mathrm{C} 2 / \mathrm{m}-\mathrm{Ca}_{2} \mathrm{C}$ at $3 \mathrm{GPa}$ has a hollow square cylinder-like Fermi shape along the $\Gamma-\mathrm{V}$ direction (that is, reciprocal lattice basis vector $\boldsymbol{b}_{3}$ direction) in the Brillouin zone (BZ), signalling quasi-2D electronic properties (see Fig. $6 \mathrm{c}$ ).

$\mathrm{Ca}_{3} \mathrm{C}_{2}$. For $\mathrm{Ca}_{3} \mathrm{C}_{2}$, no thermodynamically stable phase exists below $50 \mathrm{GPa}$. A metastable $P 4 / \mathrm{mbm}(\mathrm{Z}=2)$ phase, favoured in the pressure range from 5 to $30 \mathrm{GPa}$, transforms into a $C 2 / \mathrm{c}$ $(\mathrm{Z}=4)$ structure at $30 \mathrm{GPa}$, which is thermodynamically stable above $50 \mathrm{GPa}$. The structure of $\mathrm{P} 4 / \mathrm{mbm}-\mathrm{Ca}_{3} \mathrm{C}_{2}$ contains doubly bonded $\mathrm{C}_{2}$ groups $(\mathrm{C}-\mathrm{C}$ distance $1.39 \AA$ at $20 \mathrm{GPa})$, with an ideal charge -4 , that is, accepting four electrons from calcium atoms, leaving two electrons per formula to form $\mathrm{Ca}-\mathrm{Ca}$ bonds in this metallic compound. Metallic $C 2 / c-\mathrm{Ca}_{3} \mathrm{C}_{2}$ with a pseudogap at the Fermi level (see Supplementary Fig. 10) has singly bonded $\mathrm{C}_{2}$ groups ( $\mathrm{C}-\mathrm{C}$ bond length $1.51 \AA$ at $38.7 \mathrm{GPa}$ ), which have ideal charge -6 , exactly balanced by three $\mathrm{Ca}$ atoms in the formula.

CaC. Metallic $\mathrm{CaC}$ has two thermodynamically stable phases below $100 \mathrm{GPa}$. At $14 \mathrm{GPa}$, the metastable orthorhombic Immm structure transforms into a monoclinic $P 2_{1} / c$ structure (stable thermodynamically above $26 \mathrm{GPa}$, favoured over a wide pressure range of $14-57.5 \mathrm{GPa}$ ), followed by a thermodynamically stable Imma structure. $P 2_{1} / c-C a C$ is very interesting because its structural formula $\mathrm{Ca}_{4}\left(\mathrm{C}_{4}\right)$ contains a unique and hitherto unknown zigzag $\mathrm{C}_{4}$ group, with $\mathrm{C}-\mathrm{C}$ distances between 1.48 and $1.50 \AA$ at $14 \mathrm{GPa}$, indicating bond orders between 1 and 2 and ideal charges of about -2.5 for the end $\mathrm{C}$ atoms (Bader charge -1.447) and about -1 for the central $\mathrm{C}$ atoms (Bader charge -0.905 ).

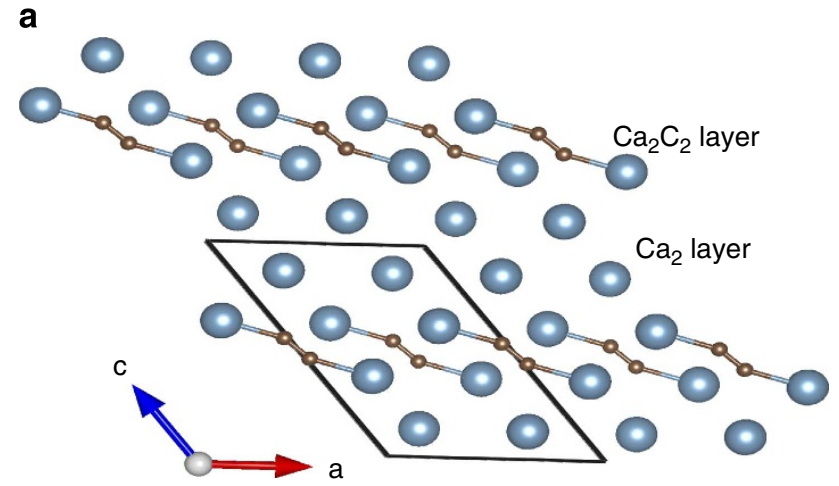

b

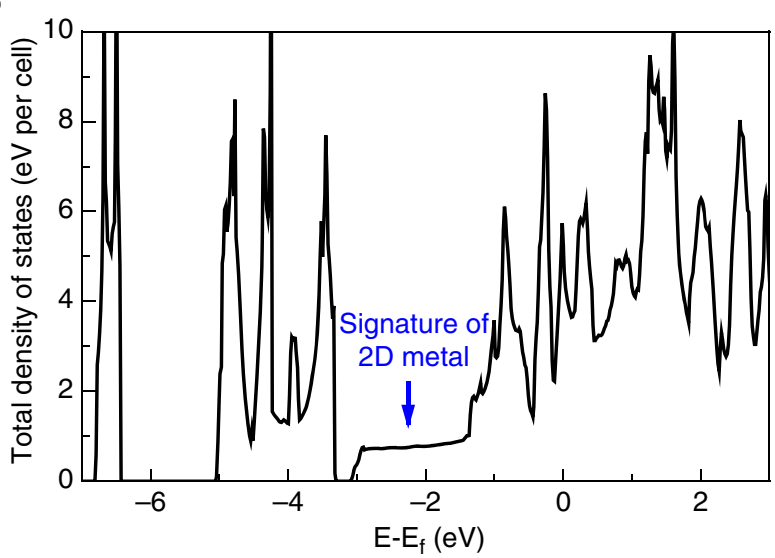

C

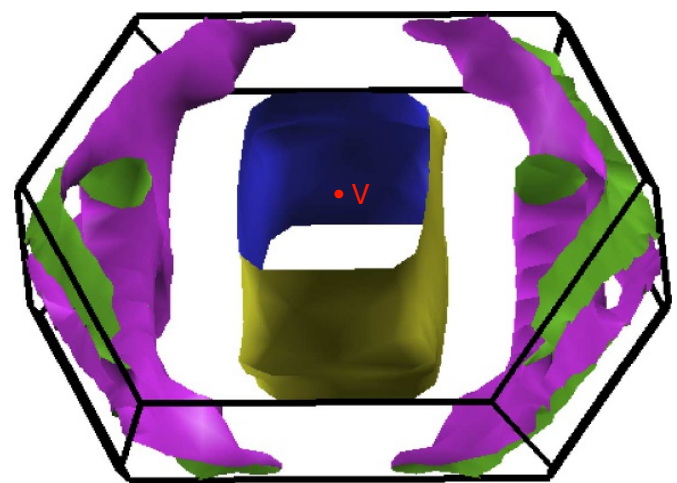

Figure 6 | Structural and electronic property of $\mathbf{C 2} / \mathrm{m}$ phase of $\mathrm{Ca}_{2} \mathrm{C}$ at $\mathbf{3} \mathbf{G P a}$. (a) The top view of $\mathrm{C} 2 / \mathrm{m}$ structure along the $y$ axis shows a clearly layered structure. (b)Total electronic density of states (DOS). (c) Fermi surface of the $\mathrm{C} 2 / \mathrm{m}$ structure. The indication of a quasi-two-dimensional metal in total DOS is confirmed by the hollow square prismatic cylinder-like Fermi surface.

Imma-CaC has infinite zigzag chains of $\mathrm{C}$ atoms $(\mathrm{C}-\mathrm{C}$ bond length of $1.55 \AA$ at $57.5 \mathrm{GPa}$, indicating a weakened single bond) in the $y$ axis direction. The structural formula of metastable Immm-CaC is $\mathrm{Ca}_{2}\left(\mathrm{C}_{2}\right)$, and with a doubly bonded $\mathrm{C}_{2}$ group $(\mathrm{C}-\mathrm{C}$ distance $1.33 \AA$ at $7.1 \mathrm{GPa}$ ) that has an ideal charge of -4 (Bader charge -2.340 ), it exactly balances the ideal charge of two Ca atoms. All three phases of $\mathrm{CaC}$ beautifully conform to the trend of increasing polymerization of the $\mathrm{C}$ sublattice with increasing pressure.

$\mathrm{Ca}_{2} \mathrm{C}_{3}$. The structure of $\mathrm{Mg}_{2} \mathrm{C}_{3}$ (space group Pnnm, $Z=2$ ), the only known alkaline-earth metal allylenide with $\mathrm{C}_{3}^{4-}$ anions ${ }^{26}$, 
was considered when searching for stable phases of $\mathrm{Ca}_{2} \mathrm{C}_{3}$. Total energy calculations exclude the possibility of the ambientpressure $\mathrm{Mg}_{2} \mathrm{C}_{3}$-type structure. The semiconducting $\mathrm{C} 2 / \mathrm{m}$ structure (band gap of $1.06 \mathrm{eV}$ at $10 \mathrm{GPa}$, see Supplementary Fig. 11) is instead the most stable one below $34.5 \mathrm{GPa}$ (thermodynamically stable from 0 to $28 \mathrm{GPa}$ ), followed by metastable $C 2 / c$ structure. By fitting energy versus volume data to the third-order Birch-Murnaghan equation of $\operatorname{stat}^{28}$, the calculated bulk modulus $B_{0}$ of $C 2 / m-\mathrm{Ca}_{2} \mathrm{C}_{3}$ is $\sim 89 \mathrm{GPa}$, which is higher than that of $\mathrm{CaC}_{2}(50 \mathrm{GPa})$. At $\sim 40 \mathrm{GPa}$, the metallic $\mathrm{C} 2 / \mathrm{c}$ structure transforms into a metastable $P-1$ structure (metal), which dominates the pressure range between 40 and $65 \mathrm{GPa}$. At higher pressures, a metallic metastable Imma structure is stable and contains zigzag carbon chains (Figs 3 and 4). We searched at much higher pressures for 3D-polymeric carbon frameworks in $\mathrm{Ca}_{2} \mathrm{C}_{3}$, but found none at pressures up to at least $300 \mathrm{GPa}$. For comparison, in $\mathrm{CaC}_{2}$ we have found that graphene sheets predicted in the high-pressure phase can be stable up to at least $1 \mathrm{TPa}$ (ref. 16).

For $\mathrm{Ca}_{2} \mathrm{C}_{3}$, the carbon arrangement changes from isolated $\mathrm{C}_{3}$ to carbon chains to ribbons (Fig. 3). The structure of $C 2 / m-\mathrm{Ca}_{2} \mathrm{C}_{3}$ can be described as $\mathrm{Ca}_{2}$ layers linked together by nearly linear symmetric $\mathrm{C}_{3}$ groups with double $\mathrm{C}-\mathrm{C}$ bonds $(\mathrm{C}-\mathrm{C}$ distances $1.32 \AA$ at $18.1 \mathrm{GPa}$ ). With this configuration, the total charge of the $\mathrm{C}_{3}$ group should be -4 (Bader charge -2.692 ), exactly compensating the charge of two $\mathrm{Ca}$ atoms in the formula (see Supplementary Table 1). Central carbon atoms in the $C_{3}$ group in this valence scheme should be neutral, and yet turn out to have a large negative Bader charge of -0.738 , whereas the end atoms, whose idealized charge is -2 , develop a lower Bader charge $(-0.977)$. This discrepancy is explained by the effects of $\mathrm{Ca}$ atoms, which form significant bonds with the central carbon atom in the $\mathrm{C}_{3}$ group and transfer some electronic charge to them. Most recently, some of us reported the prediction and synthesis of $\beta-\mathrm{Mg}_{2} \mathrm{C}_{3}$ (ref. 29), which is isostructural with our $C 2 / m-\mathrm{Ca}_{2} \mathrm{C}_{3}$ reported here. The structure of $\mathrm{C} 2 / c-\mathrm{Ca}_{2} \mathrm{C}_{3}(\mathrm{C}-\mathrm{C}$ distances $1.43-1.47 \AA$ at $34.5 \mathrm{GPa}$ ) has an idealized charge transfer scheme $\mathrm{Ca}_{2}^{4}{ }^{+} \mathrm{C}_{3}^{4-}$. In this metallic phase, $\mathrm{C}$ atoms are polymerized into infinite chains with nearly closed six-member rings running through channels of $\mathrm{Ca}$ host lattice. $P-1-\mathrm{Ca}_{2} \mathrm{C}_{3}$ features a complicated extended $1 \mathrm{D}$ ribbon of carbon atoms with nearly single $\mathrm{C}-\mathrm{C}$ bonds (lengths $1.47-1.50 \AA$ at $40 \mathrm{GPa}$ ).

Imma- $\mathrm{Ca}_{2} \mathrm{C}_{3}$ has a very interesting structure with extended $1 \mathrm{D}$ ribbons of carbon atoms cut from the graphene layer. Bond lengths in this ribbon are $1.50-1.52 \AA$ at $70 \mathrm{GPa}$, slightly longer than in graphene and indicating predominantly single bonds. Electronic structure calculations show that both $P-1$ and Imma phases of $\mathrm{Ca}_{2} \mathrm{C}_{3}$ are metals. On the basis of Allen and Dynes modified equation ${ }^{30}$, we have checked for superconductivity in these phases at 34 and $65 \mathrm{GPa}$, respectively, and found none.

$\mathrm{CaC}_{2} \cdot \mathrm{CaC}_{2}$ is thermodynamically stable above $21 \mathrm{GPa}$ (see Fig. 1a). The lower-pressure phases $C 2 / \mathrm{m}$ and $\mathrm{Cmcm}$ reported previously $^{16}$ are metastable, which could be unravelled by calculating enthalpy of formation $\left(\Delta H_{\mathrm{f}}\right)$ at lower pressure. Considering that graphite is the ground state of carbon at zero pressure, we performed additional calculations where the van der Waals interaction is accounted for by using the optPBE-van der Waals functional ${ }^{31}$. At zero pressure, the calculated $\Delta H_{\mathrm{f}}$ $\left(-0.17 \mathrm{eV}\right.$ per atom) of $\mathrm{CaC}_{2}$ is close to the experimental standard $\Delta H_{\mathrm{f}}(-0.21 \mathrm{eV}$ per atom at $298 \mathrm{~K}$ and 1 atm (ref. 32)) but higher than that $(-0.27 \mathrm{eV})$ of $\mathrm{Ca}_{2} \mathrm{C}_{3}$, confirming the thermodynamic metastability of $\mathrm{CaC}_{2}$ under ambient conditions (see Fig. 1a). It is very unexpected, but the above numbers fully confirm this conclusion, that the well-known and industrially produced compound $\mathrm{CaC}_{2}$ is metastable under ambient conditions, while the so far never seen compound $\mathrm{Ca}_{2} \mathrm{C}_{3}$ is actually stable. This could be either due to kinetics, or due to high-temperature conditions of synthesis. In addition to our previous result ${ }^{16}$, we found a new phase with the $P-1$ symmetry, which contains infinite carbon chains with five-membered rings (C-C distance is between 1.442 and $1.507 \AA$ at $20 \mathrm{GPa}$ (see Fig. 3i), signalling single or double bonds), and is the lowest enthalpy structure over a wide pressure range from 7.5 to $37 \mathrm{GPa}$ (thermodynamically stable from 21 to $37 \mathrm{GPa}$, see Fig. 4 and Supplementary Fig. 12). With further application of pressure, metallic $P-1-\mathrm{CaC}_{2}$ transforms into metallic Immm-CaC (ref. 16), in which carbon atoms are polymerized to form quasi-1D ribbons (see Figs 2-3).

Experiments. In order to confirm theoretical structure predictions, we performed synthesis under high-pressure/high-temperature conditions. Diamond anvil cells were loaded with both calcium- and carbon-rich $\mathrm{Ca}+\mathrm{C}$ mixtures, compressed to pressures up to $25 \mathrm{GPa}$, heated to temperatures up to $\sim 2,000 \mathrm{~K}$ and probed in situ using synchrotron PXRD. Under these pressure conditions, the formation of Immm-CaC,$C 2 / m-\mathrm{Ca}_{2} \mathrm{C}_{3}$ and Pnma- $\mathrm{Ca}_{2} \mathrm{C}$ may be expected on the basis of thermodynamic stabilities, as these phases are the only stable ones that appear on the convex hull up to $25 \mathrm{GPa}$ (see Fig. 1); indeed, two of these three structures were observed experimentally.

When samples were compressed above $\sim 10 \mathrm{GPa}$ and heated to $\sim 2,000 \mathrm{~K}$, mixtures of elemental glassy carbon and face-centred cubic $(f c c)$ Ca transformed into a new low-symmetry phase. After comparison with density functional theory (DFT) structure predictions, PXRD reflections originating from this phase were readily indexed to the monoclinic $\mathrm{C} 2 / m-\mathrm{Ca}_{2} \mathrm{C}_{3}$ structure with excellent agreement between experiment and theory (see Supplementary Table 3). Figure 7 shows experimental PXRD data obtained at $17 \mathrm{GPa}$ with $a=5.169(4) \AA, b=4.994(3) \AA$, $c=6.322(3) \AA$ and $\beta=128.53(3)^{\circ}$, which compares with $a=5.151 \AA, b=4.962 \AA, c=6.306 \AA$ and $\beta=128.81^{\circ}$ for the theoretical structure relaxed at $18 \mathrm{GPa}$. This sample was decompressed in steps of $\sim 2 \mathrm{GPa}$ to obtain lattice parameters as a function of pressure (see Fig. 8). Theoretical lattice parameters show an average absolute deviation of $0.3 \%$ from experiment over the entire pressure range, and the $C 2 / m-\mathrm{Ca}_{2} \mathrm{C}_{3}$ phase was recoverable to ambient pressure, but was found to be air/moisture-sensitive. The experimental $P-V$ data were fit to a second-order Birch-Murnaghan equation of state with $B_{0}=84(2)$ $\mathrm{GPa}$, in good agreement with theoretical predictions (89 GPa).

At pressures above $\sim 22 \mathrm{GPa}$, a second carbide phase (Pnma$\mathrm{Ca}_{2} \mathrm{C}$ ) was synthesized upon laser heating. This same phase was reproducibly formed both from elemental $\mathrm{Ca}+\mathrm{C}$ mixtures and from samples containing $\mathrm{C} 2 / \mathrm{m}-\mathrm{Ca}_{2} \mathrm{C}_{3}$, indicating disproportionation of $\mathrm{Ca}_{2} \mathrm{C}_{3}$ into a more stable carbide phase when pressure is raised above $\sim 22 \mathrm{GPa}$, i.e. above its predicted stability field. Figure 7 shows experimental PXRD data at $24 \mathrm{GPa}$ with $a=6.122(1) \AA, b=4.004(1) \AA, c=7.223(1) \AA$, which compares with $a=6.044 \AA, b=3.977 \AA, c=7.265 \AA$ for DFT calculations at the same pressure (see Supplementary Table 4 ). Calculated lattice parameters show an average absolute deviation of $0.5 \%$ from experimental values between 25 and $5 \mathrm{GPa}$ (see Fig. 8), which was the lowest pressure obtained due to failure of a diamond anvil. Fitting the $\mathrm{P}-\mathrm{V}$ data to a second-order Birch-Murnaghan equation of state yields $B_{0}=53(4) \mathrm{GPa}$.

\section{Discussion}

We find that the carbon sublattice within all predicted carbide phases has close correlation with the Ca:C ratio (see Fig. 2). With increasing carbon content, isolated carbon atoms are 


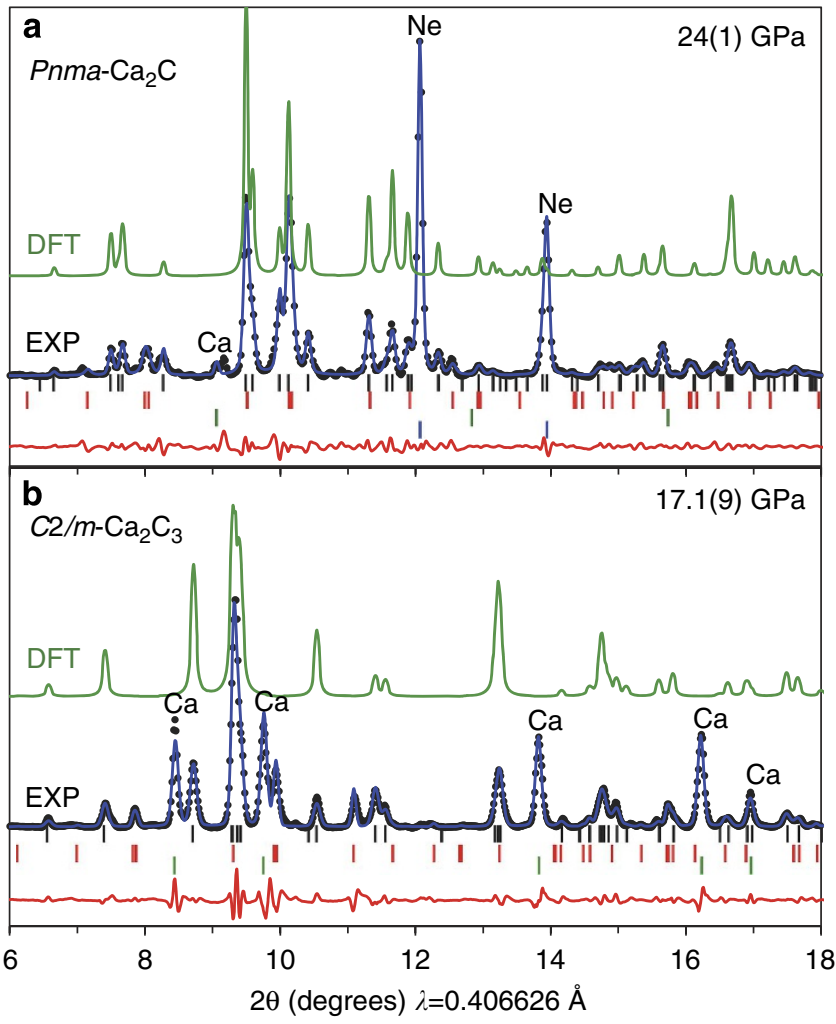

Figure 7 | PXRD patterns for experimentally observed Ca-C phases.

(a) Pnma- $\mathrm{Ca}_{2} \mathrm{C}$ synthesized at $24 \mathrm{GPa}\left(w R_{p}=1.5 \%, R_{p}=0.9 \%\right)$.

(b) $\mathrm{C} 2 / \mathrm{m}-\mathrm{Ca}_{2} \mathrm{C}_{3}$ synthesized at $17 \mathrm{GPa}\left(w R_{p}=2.0 \%, R_{p}=0.9 \%\right)$.

Experimental data (points) are compared with full-profile refinements using the Le Bail method (blue lines), with differences (red lines). Simulated powder patterns using atomic positions derived from DFT-optimized structures are shown for intensity comparison (green lines). Positions of reflections of $\mathrm{Ca}_{2} \mathrm{C}$ (a) or $\mathrm{Ca}_{2} \mathrm{C}_{3}(\mathbf{b}), \mathrm{Ca}, \mathrm{Ne}$ and a third carbide phase (see Supplementary Note 2) are indicated by black, green, blue and red tick marks, respectively.

polymerized, in turn, into $\mathrm{C}_{2}$ dumbbells, $\mathrm{C}_{3}$ and $\mathrm{C}_{4}$ groups, chains, ribbons and graphene sheets (see Fig. 4 and Supplementary Table 2). The polymeric carbon structures reveal an expected trend when comparing with the structural chemistry of the heavier congeners of group IV elements in Zintl phases (alkali or alkaline-earth silicides, germanides and stannides) ${ }^{17,33}$. Yet in spite of certain similarities to silicides, calcium carbides differ from them because of distinct bonding features. Combining present analysis and our previous results ${ }^{16,17,20}$, one can conclude that for the $\mathrm{Ca}-\mathrm{C}$ system, one can cover $s p$ to $s p^{2}$ to $s p^{2}+s p^{3}$ to $s p^{3}$ hybridizations of carbon as pressure increases. This pressureinduced structural evolution of carbon was also found in other alkali metal or alkaline-earth metal carbides ${ }^{17,20,24}$. Together with our previous results for $\mathrm{CaC}_{2}$ (ref. 16) and $\mathrm{CaC}_{6}$ (ref. 20), it is clear that a 3D network of carbon in $\mathrm{CaC}_{x}$ can be formed when $x$ is greater than 2 (from sheets to $3 \mathrm{D}$ frameworks to $\mathrm{Ca}-\mathrm{C}$ phase separation with slabs of diamond at high $\mathrm{C}$ content), consistent also with the behaviour of the metastable $\mathrm{CaC}_{4}$ compound found in our structural searches. On the other hand, the structural features of carbon-rich compounds ${ }^{20}$ can be extended to alkali-metal or alkaline-earth metal congeners of the group-IV elements, which allows one to fabricate a variety of the $3 \mathrm{D}$ framework structures of the group-IV elements by removing metal sublattices. The unexpected mechanical ${ }^{20,34}$ or electronic characteristics ${ }^{35}$ uncovered in these $3 \mathrm{D}$ framework structures pave the way to novel materials. a
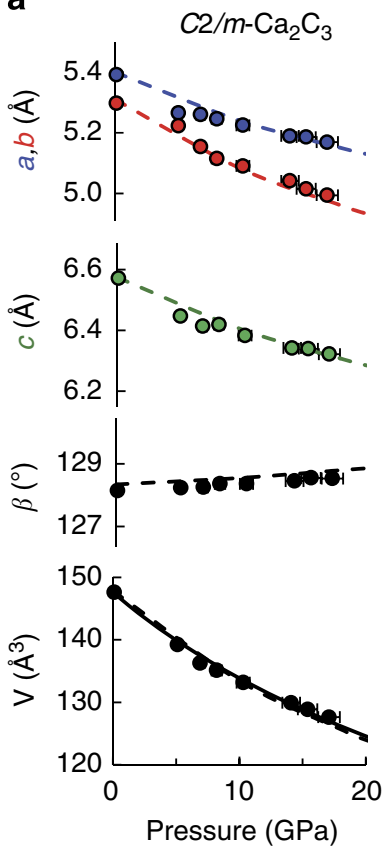

b
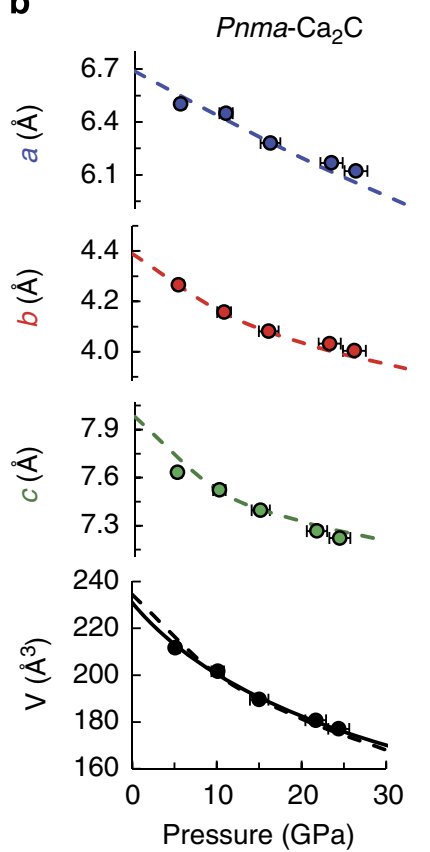

Figure 8 | Lattice parameters and unit cell volumes for $\mathrm{Ca}-\mathrm{C}$ phases. Experimental parameters (points) are compared with DFT predictions (dashed lines) for both $\mathrm{C} 2 / m-\mathrm{Ca}_{2} \mathrm{C}_{3}$ (a) and $P n m a-\mathrm{Ca}_{2} \mathrm{C}$ (b).

Experimentally-derived equations of state for both phases are shown as solid lines in the lower panels.

In summary, we have produced the first complete pressurecomposition phase diagram for $\mathrm{CaC}_{x}$ compounds at pressures up to $100 \mathrm{GPa}$ and demonstrated the experimental synthesis of two previously unknown compounds $\left(\mathrm{Ca}_{2} \mathrm{C}_{3}\right.$ and $\left.\mathrm{Ca}_{2} \mathrm{C}\right)$, validating part of our predicted phase diagram. Contrary to normal ionic compounds, there is no 'dominant' compound stable in this whole pressure range. The well-known $\mathrm{CaC}_{2}$ and $\mathrm{CaC}_{6}$ were found to be metastable at normal conditions; $\mathrm{CaC}_{2}$ is stable only above $21 \mathrm{GPa}$, and $\mathrm{CaC}_{6}$ is never thermodynamically stable, while hitherto unreported $\mathrm{Ca}_{2} \mathrm{C}_{3}$ is actually thermodynamically stable at ambient pressure. Bader analysis unravels very diverse chemistry: the decrease in $\mathrm{C}-\mathrm{C}$ bond order from triple to double to single bonds at increasing pressure; a negatively charged metal layer in calcium-rich $\mathrm{Ca}_{2} \mathrm{C}$ compound; a hitherto unknown bent linear $\mathrm{C}_{4}$ group in the $P 2_{1} / c$ phase of $\mathrm{CaC} ; \mathrm{C}$ ribbons being present in carbon-rich compounds. The $\mathrm{C} 2 / \mathrm{m}-\mathrm{Ca}_{2} \mathrm{C}$ phase provides a fresh and very attractive example of a $2 \mathrm{D}$ metal, presenting the only known example of a compound where a metal atom $(\mathrm{Ca})$ develops a negative Bader charge in presence of a more electronegative atom (C). Such unusual compounds are likely to find potential applications if synthesized in sufficiently large quantities. While powerful computational methods, such as USPEX, are capable of reliably predicting these exotic compounds, simple theoretical models capable of anticipating them are yet to be developed.

\section{Methods}

Structure search and theoretical calculations. Searches for stable structures of the $\mathrm{Ca}-\mathrm{C}$ system under compression were carried out using the evolutionary algorithm USPEX in combination with the VASP $\operatorname{code}^{36}$ on the basis of DFT within the generalized gradient approximation with the exchange-correlation functional of Perdew, Burke and Ernzerhof ${ }^{37}$, employing the projector-augmented wave ${ }^{38}$ method $[\mathrm{He}]$ and $[\mathrm{Ne}]$ cores for $\mathrm{C}$ and $\mathrm{Ca}$ atoms, respectively. For carbon, a 'hard' PAW potential was used in search for stable structures. For the crystal structure searches, we used a plane-wave basis set cutoff of $700 \mathrm{eV}$ and performed the BZ integrations using uniform Gamma-centred k-point meshes. The most 
interesting structures were further relaxed at a higher level of accuracy with a basis set cutoff of $1,000 \mathrm{eV}$ and a k-point grid of spacing $2 \pi \times 0.018 \AA^{-1}$. Iterative relaxation of atomic positions was stopped when all forces were smaller than $0.001 \mathrm{eV}^{-1}$. For compounds predicted via variable-composition searches, we researched their stable structures using fixed-composition calculations, with two, three and four formula units per unit cell. For $\mathrm{Ca}_{2} \mathrm{C}_{3}$, some evolutionary calculations were also performed under the pressure of 30,50,80,120, 160,240 and $300 \mathrm{GPa}$ with two or four chemical formula units per unit cell so as to discern the possibility of 3D network carbon.

The enthalpy of formation per atom of $\mathrm{Ca}_{n} \mathrm{C}_{m}$ is defined as $\Delta H_{f}\left(\mathrm{Ca}_{n} \mathrm{C}_{m}\right)=\left[H\left(\mathrm{Ca}_{n} \mathrm{C}_{m}\right)-n H(\mathrm{Ca})-m H(\mathrm{C})\right] /(n+m)$, where all enthalpies $H$ are given at the same pressure and zero temperature. At a given pressure, the calcium carbides located on the convex hull are thermodynamically stable against decomposition to any other binaries or the elements, while the compounds above the convex hull are meta-stable.

The Bader analysis was performed for exploring chemical bonding and local electrons ${ }^{39}$. To get a converged charge density, the plane wave kinetic energy cutoff of $1,000 \mathrm{eV}$ and Monkhorst-Pack k-point meshes with the reciprocal space resolution of $2 \pi \times 0.02 \AA^{-1}$ were used for all the structures. A series of FFT grids to accurately reproduce the correct total core charge were tested by increasing parameters $\mathrm{NG}(\mathrm{X}, \mathrm{Y}, \mathrm{Z}) \mathrm{F}$ to $1.5,2$ and 2.5 times the default one.

The lattice dynamics and superconducting properties of $\mathrm{Ca}_{2} \mathrm{C}_{3}$ were calculated by the Quantum ESPRESSO package ${ }^{40}$ using Vanderbilt-type ultrasoft pseudopotentials with cutoff energies of 50 and $500 \mathrm{Ry}$ for the wave functions and the charge density, respectively. The electronic BZ integration in the phonon calculation was based on a $12 \times 12 \times 12$ of Monkhorst-Pack k-point meshes. The dynamical matrix was computed on the basis of a $6 \times 6 \times 6$ mesh of phonon wave vectors. The electron-phonon coupling was convergent with a finer grid of $48 \times 48 \times 48 \mathbf{k}$ points and a Gaussian smearing of $0.01 \mathrm{Ry}$. For other compounds, phonon calculations were performed using the Phonopy code ${ }^{41}$. The Fermi surface of $C 2 / m-\mathrm{Ca}_{2} \mathrm{C}$ at $3 \mathrm{GPa}$ was calculated using Quantum Espresso and $16 \times 16 \times 8$ of Monkhorst-Pack k-point mesh.

Experiment. Reagents for experimental studies consisted of commercial calcium metal (Sigma-Aldrich, dendritic pieces, 99.99\%) and glassy carbon (Sigma-Aldrich, $2-12 \mu \mathrm{m}, 99.95 \%)$. The carbon powder was degasified for $12 \mathrm{~h}$ at $\sim 200^{\circ} \mathrm{C}$ in a vacuum oven and then sealed under Ar. Diamond anvil cell syntheses (up to $25 \mathrm{GPa}$ and 2,000 K with in situ PXRD) were performed at High Pressure Collaborative Access Team (HPCAT), sector 16, of the Advanced photon Source. A small amount of carbon powder and Ca metal shavings were pressed in thin layers within a rhenium gasket in a diamond anvil cell equipped with $400-\mu \mathrm{m}$ culet diamonds inside of an inert Ar glovebox $\left(\mathrm{O}_{2}<1\right.$ p.p.m.; $\mathrm{H}_{2} \mathrm{O}<1$ p.p.m.). It was not possible to control the precise $\mathrm{Ca}: \mathrm{C}$ ratio; however, compositions were estimated to range between $0.333 \leq \mathrm{Ca}: \mathrm{C} \leq 3$, on the basis of the volume of material loaded into the diamond cell. Samples were sealed inside the glovebox without pressure medium or loaded with Ne to improve thermal isolation from diamonds and quasihydrostatic conditions for subsequent diffraction measurements. Pressure was estimated using the Ne equation of state ${ }^{42}$ and/or with a ruby gauge ${ }^{43}$. To generate high temperatures, samples were heated on both sides using infrared fibre lasers. In some cases two or three heating cycles were performed, with X-ray diffraction patterns collected before, during and after laser heating. During laser heating, temperatures from each side of the sample were estimated by collecting emitted thermal radiation, correcting for the optical system response and fitting the spectral data to Planck's equation. Angle-dispersive PXRD patterns were collected using a mar345 detector (marXperts GmbH, Norderstedt, Germany) image plate calibrated with a $\mathrm{CeO}_{2}$ standard. Patterns were integrated using FIT2D (ref. 44) and phase recognition and indexing were performed using PowderCell and CheckCell programmes ${ }^{45}$. While observed PXRD intensities were in good agreement with DFT-derived structural models, observed powder statistics were not suitable for Rietveld refinements. Full profile refinements were performed using the Le Bail intensity extraction method, as implemented in $\mathrm{GSAS}^{46}$ with EXPGUI ${ }^{47}$ (see Supplementary Figs 13-15 and Supplementary Note 2 for additional details).

\section{References}

1. Lyakhov, A. O., Oganov, A. R., Stokes, H. T. \& Zhu, Q. New developments in evolutionary structure prediction algorithm USPEX. Comput. Phys. Commun. 184, 1172-1182 (2013).

2. Zhu, Q., Oganov, A. R. \& Lyakhov, A. O. Novel stable compounds in the $\mathrm{Mg}-\mathrm{O}$ system under high pressure. Phys. Chem. Chem. Phys. 15, 7696-7700 (2013).

3. Zhang, W. et al. Unexpected stable stoichiometries of sodium chlorides. Science 342, 1502-1505 (2013).

4. Lobanov, S. S. et al. Stable magnesium peroxide at high pressure. Preprint at http://arxiv.org/abs/1502.07381 (2015).

5. Zhu, Q., Zeng, Q. \& Oganov, A. R. Systematic search for low-enthalpy $\mathrm{sp}^{3}$ carbon allotropes using evolutionary metadynamics. Phys. Rev. B 85, 201407 (2012).

6. Oganov, A. R. et al. Exotic behavior and crystal structures of calcium under pressure. Proc. Natl Acad. Sci. USA 107, 7646-7651 (2010).
7. Fujihisa, H. et al. Ca-VII: A chain ordered host-guest structure of calcium above 210 GPa. Phys. Rev. Lett. 110, 235501 (2013).

8. Sakata, M., Nakamoto, Y., Shimizu, K., Matsuoka, T. \& Ohishi, Y. Superconducting state of Ca-VII below a critical temperature of $29 \mathrm{~K}$ at a pressure of $216 \mathrm{GPa}$. Phys. Rev. B 83, 220512 (2011).

9. Oganov, A. R. \& Glass, C. W. Crystal structure prediction using ab initio evolutionary techniques: principles and applications. J. Chem. Phys. 124, 244704-244715 (2006)

10. Li, Q. et al. Superhard monoclinic polymorph of carbon. Phys. Rev. Lett. 102, 175506-175504 (2009).

11. Boulfelfel, S. E., Oganov, A. R. \& Leoni, S. Understanding the nature of 'superhard graphite'. Sci. Rep. 2, 471 (2012).

12. Wang, Y., Panzik, J. E., Kiefer, B. \& Lee, K. K. M. Crystal structure of graphite under room-temperature compression and decompression. Sci. Rep. 2, 520 (2012).

13. Nylen, J., Konar, S., Lazor, P., Benson, D. \& Haussermann, U. Structural behavior of the acetylide carbides $\mathrm{Li}_{2} \mathrm{C}_{2}$ and $\mathrm{CaC}_{2}$ at high pressure. J. Chem. Phys. 137, 224507-224508 (2012).

14. Gauzzi, A. et al. Enhancement of superconductivity and evidence of structura instability in intercalated graphite $\mathrm{CaC}_{6}$ under high pressure. Phys. Rev. Lett. 98, 067002-067004 (2007).

15. Debessai, M. et al. Superconductivity for $\mathrm{CaC}_{6}$ to $32 \mathrm{GPa}$ hydrostatic pressure. Phys. Rev. B 82, 132502 (2010).

16. Li, Y.-L. et al. Pressure-induced superconductivity in $\mathrm{CaC}_{2}$. Proc. Natl Acad. Sci. USA 110, 9289-9294 (2013).

17. Benson, D. et al. Lithium and calcium carbides with polymeric carbon structures. Inorg. Chem. 52, 6402-6406 (2013).

18. Zhang, L. et al. Pressure-induced enhancement of electron-phonon coupling in superconducting $\mathrm{CaC}_{6}$ from first principles. Phys. Rev. B 74, 184519 (2006).

19. Csányi, G., Pickard, C. J., Simons, B. D. \& Needs, R. J. Graphite intercalation compounds under pressure: a first-principles density functional theory study. Phys. Rev. B 75, 085432 (2007).

20. Li, Y.-L. et al. Formation of nanofoam carbon and re-emergence of superconductivity in compressed $\mathrm{CaC}_{6}$. Sci. Rep. 3, 3331 (2013).

21. Oganov, A. R., Lyakhov, A. O. \& Valle, M. How evolutionary crystal structure prediction works-and why. Acc. Chem. Res. 44, 227-237 (2011).

22. Pickard, C. J. \& Needs, R. J. Dense low-coordination phases of lithium. Phys. Rev. Lett. 102, 146401-146404 (2009).

23. Ma, Y. et al. Transparent dense sodium. Nature 458, 182-185 (2009).

24. Wang, D.-H. et al. BaC: a thermodynamically stable layered superconductor. Phys. Chem. Chem. Phys. 16, 20780-20784 (2014).

25. Kurakevych, O. O., Strobel, T. A., Kim, D. Y. \& Cody, G. D. Synthesis of $\mathrm{Mg}_{2} \mathrm{C}$ : a magnesium methanide. Angew. Chem. Int. Ed. 52, 8930-8933 (2013).

26. Ruschewitz, U. Binary and ternary carbides of alkali and alkaline-earth metals. Coord. Chem. Rev. 244, 115-136 (2003).

27. Feng, J., Hennig, R. G., Ashcroft, N. W. \& Hoffmann, R. Emergent reduction of electronic state dimensionality in dense ordered Li-Be alloys. Nature 451, 445-448 (2008).

28. Birch, F. Finite elastic strain of cubic crystals. Phys. Rev. 71, 809-824 (1947).

29. Timothy, A. S. et al. Synthesis of $\beta-\mathrm{Mg}_{2} \mathrm{C}_{3}$ : a monoclinic high-pressure polymorph of magnesium sesquicarbide. Inorg. Chem. 53, 7020-7027 (2014).

30. Allen, P. B. \& Dynes, R. C. Transition temperature of strong-couplied superconductors reanalyzed. Phys. Rev. B 12, 905-922 (1975).

31. Klimeš, J., Bowler, D. R. \& Michaelides, A. Van der Waals density functionals applided to solids. Phys. Rev. B 83, 195131 (2011).

32. Standard enthalpy change of formation http://en.wikipedia.org/wiki/ (2014).

33. Gao, G., Ashcroft, N. W., Miao, M. \& Hoffmann, R. Novel Si networks in the $\mathrm{Ca} / \mathrm{Si}$ phase diagram under pressure. J. Phys. Chem. C 118, 25167-25175 (2014).

34. Jiang, X., Zhao, J., Li, Y. L. \& Ahuja, R. Tuable assembly of sp3 cross-linked 3D graphene monoliths: a first-principles prediction. Adv. Funct. Mater. 23, 5846-5853 (2013).

35. Kim, D. Y., Stefanoski, S., Kurakevych, O. O. \& Strobel, T. A. Synthesis of an open-framework allotrope of silicon. Nat. Mater. 14, 169-173 (2015).

36. Hafner, J. Materials simulations using VASP - a quantum perspective to materials science. Comput. Phys. Commun. 177, 6-13 (2007).

37. Perdew, J. P., Burke, K. \& Ernzerhof, M. Generalized gradient approximation made simple. Phys. Rev. Lett. 77, 3865-3868 (1996).

38. Kresse, G. \& Joubert, D. From ultrasoft pseudopotentials to the projector augmented-wave method. Phys. Rev. B 59, 1758-1775 (1999).

39. Henkelman, G., Arnaldsson, A. \& Jónsson, H. A fast and robust algorithm for Bader decomposition of charge density. Comp. Mater. Sci. 36, 354-360 (2006)

40. Giannozzi, P. et al. QUANTUM ESPRESSO: a modular and open-source software project for quantum simulations of materials. J. Phys. Condens. Mater. 21, 395502 (2009).

41. Togo, A., Oba, F. \& Tanaka, I. First-principles calculations of the ferroelastic transition between rutile-type and $\mathrm{CaCl}_{2}$-type $\mathrm{SiO}_{2}$ at high pressures. Phys. Rev. B 78, 134106 (2008). 
42. Hemley, R. J. et al. X-ray diffraction and equation of state of solid neon to 110 GPa. Phys. Rev. B 39, 11820-11827 (1989).

43. Mao, H. K., Xu, J. \& Bell, P. M. Calibration of the ruby pressure gauge to 800 kbar under quasi-hydrostatic conditions. J. Geophys. Res. Solid Earth 91, 4673-4676 (1986).

44. Hammersley, A. P. FIT2D: an Introduction and Overview. ESRF Internal Report ESRF97HA02T. European Synchrotron Radiation Facility, Grenoble, France (1997).

45. LMGP-suite suite of programs for the interpretation of X-ray experiments, by Jean Laugier and Bernard Bochu, ENSP/Laboratoire des Matériaux et du Génie Physique, BP 46. 38042 Saint Martin d'Hères, France.

46. Larson, A. C. \& Von Dreele, R. B. Los Alamos National Laboratory Report LAUR 86-748 (1994).

47. Toby, B. H. EXPGUI, a graphical user interface for GSAS. J. Appl. Crystallogr. 34, 210-213 (2001).

\section{Acknowledgements}

Y.-L.L. acknowledges support from the NSFC (11347007), Qing Lan Project and the Priority Academic Program Development of Jiangsu Higher Education Institutions (PAPD). A.R.O. and S.-N.W. thank the National Science Foundation (EAR-1114313, DMR-1231586), DARPA (Grants No. W31P4Q1210008 and No. W31P4Q1310005), the Government of Russian Federation (No. 14.A12.31.0003) for financial support and the Foreign Talents Introduction and Academic Exchange Program (No. B08040). Calculations were performed on XSEDE facilities and on the cluster of the Center for Functional Nanomaterials, Brookhaven National Laboratory, which is supported by the DOE-BES under contract no. DE-AC02-98CH10086. Experimental efforts were supported by DARPA under grant No. W31P4Q1310005. Portions of this work were performed at HPCAT (Sector 16), Advanced Photon Source, Argonne National Laboratory. HPCAT operations are supported by DOE-NNSA under Award No. DE-NA0001974 and
DOE-BES under Award No. DE-FG02-99ER45775, with partial instrumentation funding by NSF. The Advanced Photon Source is a US Department of Energy (DOE) Office of Science User Facility operated for the DOE Office of Science by Argonne National Laboratory under Contract No. DE-AC02-06CH11357.

\section{Author contributions}

Y.-L.L. and A.R.O. designed the research. T.A.S. designed the experiments. Y.-L.L. A.R.O. and S.-N.W. performed calculations. H.G., J.S.S. and T.A.S. performed the experimental studies. All authors analysed the data and contributed to write the paper.

\section{Additional information}

Supplementary Information accompanies this paper at http://www.nature.com/ naturecommunications

Competing financial interests: The authors declare no competing financial interests.

Reprints and permission information is available online at http://npg.nature.com/ reprintsandpermissions/

How to cite this article: Li, Y. L. et al. Investigation of exotic stable calcium carbides using theory and experiment. Nat. Commun. 6:6974 doi: 10.1038/ncomms7974 (2015).

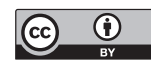

This work is licensed under a Creative Commons Attribution 4.0 International License. The images or other third party material in this article are included in the article's Creative Commons license, unless indicated otherwise in the credit line; if the material is not included under the Creative Commons license, users will need to obtain permission from the license holder to reproduce the material. To view a copy of this license, visit http://creativecommons.org/licenses/by/4.0/ 